\title{
Pengukuran Frekuensi Bunyi Saron Demung Laras Pelog Gamelan Jawa Menggunakan Perangkat Lunak Visual Analyser
}

\author{
Mitrayana dan V. J. Cytasari \\ Jurusan Fisika, FMIPA UGM \\ Sekip Utara Unit III BLS 21 Yogyakarta \\ mitrayana@ugm.ac.id
}

\begin{abstract}
Abstrak - Penelitian 'PENGUKURAN FREKUENSI BUNYI SARON DEMUNG LARAS PELOG GAMELAN JAWA MENGGUNAKAN PERANGKAT LUNAK VISUAL ANALYSER` ditujukan untuk mengkaji karakteristik frekuensi bunyi pada Gamelan khususnya Saron Demung Laras Pelog. Saron Demung Laras Pelog merupakan alat musik tradisional yang belum mempunyai standar nada seperti alat musik lainnya. Penyelarasan gamelan dewasa ini biasanya dilakukan oleh para ahli, yaitu hanya dengan menggunakan rasa jiwa berdasarkan pengalamanya. Tiap gamelan yang dihasilkan memiliki perbedaan pada setiap penyelarasnya. Sehingga diharapkan hasil dari penelitian ini dapat digunakan untuk penentuan standarisasi pada alat musik gamelan khususnya Saron Demung Laras Pelog. Penelitian dilakukan dengan menggunakan mikrofon yang dihubungkan langsung ke komputer jinjing. Komputer jinjing ini telah dilengkapi dengan perangkat lunak Visual Analyser yang langsung dapat menampilkan spektrum dan nilai frekuensi dari bunyi gamelan yang diamati. Dengan melakukan penabuhan yang konstan pada setiap wilahannya maka dapat diperoleh nilai frekuensi resonansi dari Saron Demung Laras Pelog baik langsung pada kolom frequency meter maupun dengan menggeser kursor pada puncak amplitudo maksimumnya. Frekuensi resonansi rata-rata $\left(f_{0}\right)$ dan nilai ketidakpastian ralatnya $\left(\Delta f_{0}\right)$ yang diperoleh dari penelitian untuk Saron Demung Laras Pelog berturut-turut dari wilahan 1 sampai 7 yaitu $(289 \pm 6) \mathrm{Hz},(319 \pm 7) \mathrm{Hz},(336 \pm 7) \mathrm{Hz},(392 \pm 8)$ $\mathrm{Hz},(429 \pm 8) \mathrm{Hz},(455 \pm 8) \mathrm{Hz}$, dan $(505 \pm 9) \mathrm{Hz}$.
\end{abstract}

Kata kunci : frekuensi, bunyi, Saron Demung.

\begin{abstract}
The research on “THE SOUND FREQUENCY MEASUREMENT OF JAVANESE GAMELAN'S SARON DEMUNG LARAS PELOG WITH VISUAL ANALYSER SOFTWARE” is aimed at investigating the frequency characteristics of sound on gamelan, especially Saron Demung Laras Pelog. Saron Demung Laras Pelog is a traditional music instrument which does not have standard tuning like other musical instruments yet. Currently, gamelan tuning is usually carried out by experts, that is by using their feeling based on their experience. Each gamelan produced is different in its tuning. Therefore, it is expected that the result of this research can be used as a standardization of gamelan musical instrument, especially Saron Demung Laras Pelog. The research was carried out by using a microphone connected directly to a computer. The computer was supported by Visual Analyser, a software that can display spectrum and frequency of the sound of the observed gamelan. By hitting constantly on each 'wilahan', the value of resonance frequency of Saron Demung Laras Pelog was obtained either from frequency meter column directly or by dragging the cursor to the peak of maximum amplitude. The research results indicate that the average resonance frequency $\left(f_{0}\right)$ and the uncertainty value $\left(\Delta f_{0}\right)$ for Saron Demung Laras Pelog from key 1 through 7 are $(289 \pm 6) \mathrm{Hz},(319 \pm 7) \mathrm{Hz},(336 \pm 7) \mathrm{Hz},(392 \pm 8) \mathrm{Hz},(429 \pm 8) \mathrm{Hz},(455 \pm 8) \mathrm{Hz}$, and (505 \pm 9$) \mathrm{Hz}$ respectively.
\end{abstract}

Keyword : frequency, sound, Saron Demung

\section{PENDAHULUAN}

Gamelan dirancang secara manual dan ditera oleh pembuatnya dengan perasaan mereka sendiri berdasarkan pengalaman. Indera pendengaran manusia dapat membedakan tinggi-rendahnya nada, namun tidak dapat mengetahui secara pasti jenis nada apa yang didengar olehnya. Hal ini sangatlah penting bagi seorang pemusik untuk mengetahui apakah alat musiknya sudah menghasilkan nada-nada yang tepat.

Program komputer dapat melakukan penalaan nada alat musik dengan menghitung frekuensi dasar gelombang bunyi alat musik tersebut dari hasil alihragam Fourier dan mencocokkan frekuensi dasar tersebut dengan frekuensi dasar nada referensi yang baku. Dengan demikian jenis nada alat musik dapat diketahui secara pasti untuk melakukan penalaan nada alat musik. Sehingga penelitian yang secara khusus mengkaji tentang gamelan membuka peluang untuk menjadikan penelitian bidang gamelan yang mengaplikasikan konsep ilmiah teori akustik yang termasuk dalam penelitian bidang seni dan sastra untuk mendukung industri kreatif.

Adapun tujuan dari eksperimen yang dilakukan adalah:

1. Menganalisis spektrum getaran setiap wilahan dari hasil yang ditunjukkan oleh Visual Analyser.

2. Menentukan nilai frekuensi resonansi setiap wilahan Saron Demung Laras Pelog $\left(f_{0} \pm \Delta f_{0}\right)$. 
3. Mengetahui keakuratan perangkat lunak Visual Analyser untuk mengukur frekuensi resonansi Saron Demung Laras Pelog $\left(\Delta f_{0}\right)$.

4. Mengetahui faktor-faktor yang mempengaruhi ketidakselarasan Saron Demung Laras Pelog.

II. METODE PENELITIAN

A. Skema Kalibrasi Alat

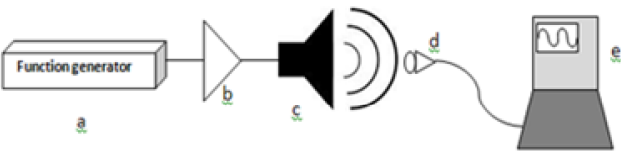

Gambar 1 Skema Kalibrasi Alat. a. Function Generator; b. Amplifier; c. Speaker; d. Mikrofon; e. Komputer jinjing dilengkapi perangkat lunak Visual Analyser.

Skema kalibarasi ditunjukkanp pada Gambar 1 . Perangkat lunak Visual Analyser dikalibrasi dengan function generator. Kalibrasi dilakukan dengan membandingkan nilai frekuensi yang dihasilkan oleh function generator dengan nilai frekuensi yang terbaca pada perangkat lunak Visual Analyser.

\section{B. Skema Percobaan pada Pengambilan Data Saron Demung}

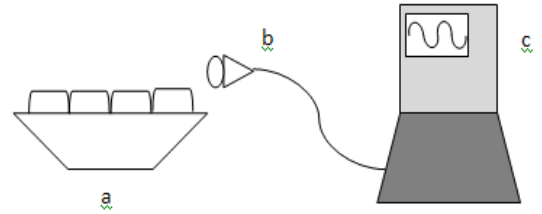

Gambar 2 Skema Percobaan pada Saron Demung.

a. Saron Demung Laras Pelog; b. Mikrofon; c. Komputer jinjing dilengkapi perangkat lunak Visual Analyser

Gambar 2 menunjukkan skema percobaan yang dilakukan untuk mengambil dan menyimpan data eksperimen dari Saron Demung.

\section{Skema Penabuh Gamelan}

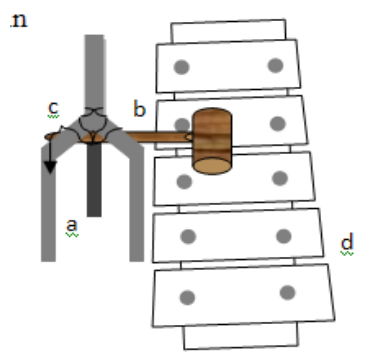

Gambar 3 Skema Penabuh Wilahan Saron Demung Laras Pelog. a. Statis besi; b.Tabuh Kayu; c. Tali Ban d. Saron Demung Laras Pelog

Gambar 3 merupakan skema penabuh pada wilahan saron demung. Pengambilan data pada setiap wilahan dilakukan sebanyak 50 kali dengan tekanan pada tabuh yang dianggap konstan. Perangkat lunak Visual Analyser yang telah terinstal pada komputer jinjing disertai dengan mikrofon yang terpasang langsung pada komputer jinjing dan diletakkan di dekat wilahan yang sedang diamati. Nilai frekuensi resonansi dapat langsung terbaca pada kolom frequency meter maupun dari puncak amplitude maksimum dari spektrum bunyi yang dihasilkan pada Visual Analyser bersamaan ketika melakukan penabuhan pada Saron Demung.

\section{HASIL DAN PEMBAHASAN}

\section{A. Hasil Kalibrasi}

Untuk memperoleh keakuratan data pada penelitian dilakukan pembandingan $f_{F G}$ dan $f_{V A}$ seperti yang ditunjukkan pada grafik hasil kalibrasi pada gambar 4 . Dengan persamaan linieritas yang dihasilkan selanjutnya digunakan dalam penghitungan nilai frekuensi dari hasil penelitian.

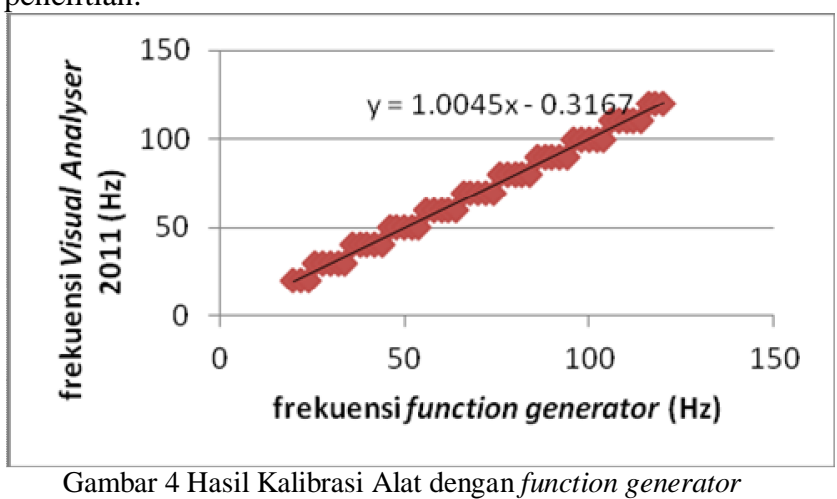

Rumus dan Penghitungan Nilai Frekuensi Resonansi dan Ketidakpastian Frekuensi Resonansi Penelitian

$$
\begin{aligned}
& f_{V A}=1,004 f_{F G}-0,316=m f_{F G}-c \\
& f_{0}=f_{F G}=\frac{f_{V A} \| 0,316}{1,004}=\frac{f_{V A} \| c}{m} \\
& \Delta f_{0}=\sqrt{\left(\frac{\partial f_{F G}}{\partial f_{V A}} \Delta f_{V A}\right)^{2}+\left(\frac{\partial f_{F G}}{\partial m} \Delta m\right)^{2}+\left(\frac{\partial f_{F G}}{\partial c} \Delta c\right)^{2}} \\
& \Delta f_{0}=\sqrt{\left(\frac{1}{m} \Delta f_{V A}\right)^{2}+\left(-\frac{f_{V A}}{m^{2}} \Delta m\right)^{2}+\left(-\frac{c}{m^{2}} \Delta m\right)^{2}+\left(\frac{1}{m} \Delta c\right)^{2}} \\
& \text { dengan } m=1,004, \Delta m=0.001, \Delta f_{\mathrm{VA}}=5, \quad c=0,316, \Delta c=0,003 .
\end{aligned}
$$

\section{B. Hasil Spektrum Frekuensi Saron Demung}

Gambar 5 merupakan gambar hasil dari spektrum frekuensi dari Saron Demung Laras Pelog, teramati amplitudo maksimum pada jangkauan frekuensi $280-520$ Hz. 


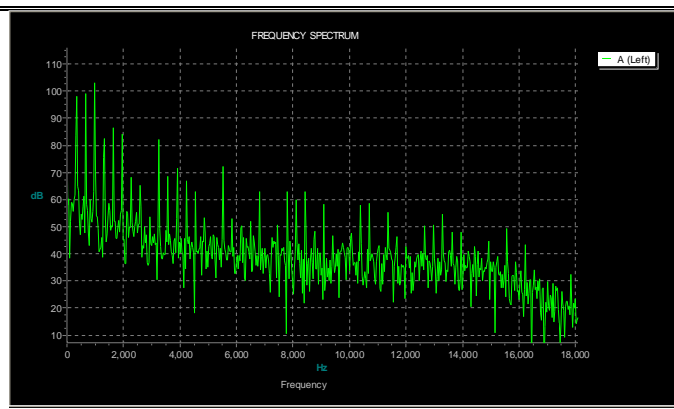

Gambar 5 Hasil Spektrum Bunyi Saron Demung

\section{Perbandingan Hasil penelitian dengan Referensi}

Berdasarkan ukuran tiap Saron Demung laras pelog yang telah diamati, pada setiap pangkon yang memiliki wilahan 1 sampai 7 jika ditinjau dengan mengamati besarnya lebar tiap wilahan dan mengasumsikan ketebalannya sama terlihat semakin kecil luasannya dihasilkan nilai frekuensi resonansi yang semakin besar. Hal ini menunjukkan bahwa memang benar adanya dengan $f_{0}$ frekuensi resonansi dan $L$ adalah lebar wilahan $[1,2]$,

$$
f_{0} \times \frac{1}{L}
$$

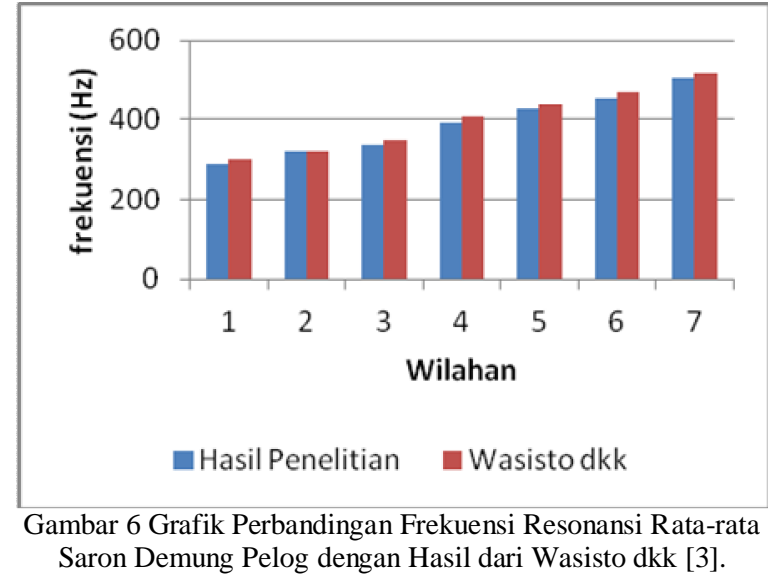

Tabel 1 Nilai Frekuensi Resonansi pada Wilahan Saron Demung Pelog

\begin{tabular}{|c|c|c|c|}
\hline \multirow{2}{*}{ Wilahan } & \multicolumn{3}{|c|}{ frekuensi (Hz) } \\
\cline { 2 - 4 } & Penelitian & $\begin{array}{c}\text { Wasisto } \\
\text { dkk }^{[3]}\end{array}$ & Perbedaan \\
\hline 1 & 289 & 299 & 10 \\
\hline 2 & 319 & 320 & 1 \\
\hline 3 & 336 & 347 & 11 \\
\hline 4 & 392 & 406 & 14 \\
\hline 5 & 429 & 440 & 11 \\
\hline 6 & 455 & 470 & 15 \\
\hline 7 & 505 & 519 & 14 \\
\hline
\end{tabular}

Akan tetapi jika dibandingkan dengan pangkon lainnya ada kalanya dengan ukuran wilahan yang sama frekuensi resonansi yang dihasilkan berbeda. Hal ini disebabkan banyak faktor yang mempengaruhi nada dari gamelan, yaitu kualitas material yang digunakan, kayu yang digunakan sebagai papan pangkon, usia dari gamelan tersebut dan yang paling penting yaitu lubang resonator yang terdapat di bawah tiap-tiap wilahannya. Fungsi dari resonator selain tempat udara berresonansi juga penguat suara yang dihasilkan akibat getaran yang dihasilkan akibat penabuhan pada wilahan gamelan di atasnya.

Dari setiap wilahan yang diamati pada ketiga sampel Saron Demung, diperoleh nilai rata-rata frekuensi resonansinya disajikan pada tabel 1 . Ditunjukkan nilai perbedaan antara rata-rata frekuensi yang dihasilkan dengan hasil penelitian Wasisto dkk [3]. Secara lebih jelas disajikan dalam grafik pada gambar 6. Nilai frekuensi dari hasil penelitian ini dapat dikatakan lebih rendah dari hasil penelitian Wasisto dkk[3]. Akan tetapi tidak terpaut jauh dan masih masuk pada jangkauan data. Nilai rata-rata yang diperoleh dari frekuensi resonansi tiap-tiap wilahan Saron Demung Laras Pelog yaitu $(289 \pm 60 \mathrm{~Hz},(319 \pm 7) \mathrm{Hz}$, (336 \pm 7$) \mathrm{Hz},(392 \pm 8) \mathrm{Hz},(429 \pm 8) \mathrm{Hz},(455 \pm 8) \mathrm{Hz}$, dan $(505 \pm 9) \mathrm{Hz}$. Angka ralat tersebut menunjukkan nilai ketelitian dari kualitas perangkat lunak Visual Analyser untuk mengolah data dari sumber bunyi gamelan yang telah dikalibrasi dengan function generator di Laboratorium Akustik Lab. Fisika Atom dan Inti Jurusan Fisika FMIPA UGM.

Pada perangkat lunak Visual Analyser ini apabila dilakukan pembesaran pada puncak-puncak spektrumnya terlihat pengambilan sampel pada domain waktu ke domain frekuensi sebesar $10 \mathrm{~Hz}$, sehingga tidak dapat diamati lebih teliti pada jangkauan nilai frekuensi yang tidak ditampilkan pada spektrum frekuensi. Spektrum frekuensi yang dihasilkan dapat diperbesar hingga lima angka dibelakang koma, hingga dapat diketahui puncak-puncak amplitudo dengan jelas. Akan tetapi dengan pembesaran ini pula dapat terlihat jika kualitas ketelitian dari perangkat lunak tersebut hanya memperlihatkan puncak-puncak setiap $10 \mathrm{~Hz}$. Dapat disimpulkan bahwa perangkat lunak ini kurang cocok digunakan untuk mengukur frekuensi dengan ketelitian tinggi yang sensitif terhadap perubahan. Akan tetapi perangkat lunak ini baik digunakan untuk mengukur intensitas bunyi, Karena intensitas (dB) yang ditampilkan dalam perangkat ini dalam ketelitian dua angka dibelakang koma sehingga memiliki ketelitian tinggi untuk mengukur intensitas $(\mathrm{dB})$.

\section{IV.KESIMPULAN}

Berdasarkan hasil penelitian karakteristik frekuensi pada nada dasar Saron Demung Laras pelog yang telah dilakukan maka dapat disimpulkan bahwa:

1. Spektrum bunyi dari Saron Demung Laras Pelog menunjukkan amplitudo maksimum pada jangkauan frekuensi $280-520 \mathrm{~Hz}$.

2. Diperoleh nilai rata-rata frekuensi resonansi beserta nilai ketidakpastian ralatnya pada tiap wilahan Saron Demung Laras Pelog yang diamati yaitu :

Wilahan $1 f_{0} \pm \Delta f_{0}=(289 \pm 6) \mathrm{Hz}$ 
Wilahan $2 f_{0} \pm \Delta f_{0}=(319 \pm 7) \mathrm{Hz}$

Wilahan $3 f_{0} \pm \Delta f_{0}=(336 \pm 7) \mathrm{Hz}$

Wilahan $4 f_{0} \pm \Delta f_{0}=(392 \pm 8) \mathrm{Hz}$

Wilahan $5 f_{0} \pm \Delta f_{0}=(429 \pm 8) \mathrm{Hz}$

Wilahan $6 f_{0} \pm \Delta f_{0}=(455 \pm 8) \mathrm{Hz}$

Wilahan $7 f_{0} \pm \Delta f_{0}=(505 \pm 9) \mathrm{Hz}$

3. Ketelitian perangkat lunak Visual Analyser 2011 untuk mengukur frekuensi resonansi Saron Demung Laras Pelog $\left(\Delta f_{0}\right)$ adalah $5 \mathrm{~Hz}$.

4. Faktor-faktor yang mempengaruhi frekuensi resonansi $\left(f_{0}\right)$ pada Wilahan Saron demung Laras Pelog yaitu ukuran tiap wilahan baik panjang lebar maupun ketebalannya. Selain itu ukuran lubang resonator di bawah wilahan juga berpengaruh pada frekuensi resonansi $\left(f_{0}\right)$ yang dihasilkan.
UCAPAN TERIMAKASIH

Ucapan terimakasih kami haturkan kepada Jurusan Fisika FMIPA UGM yang telah membiaya pelaksanaan seminar ini, dan kepada Kelompok Kesenian UGM yang telah menginjinkan penggunaan gamelan untuk bahan penelitian.

\section{DAFTAR PUSTAKA}

[1] Carlson,A.Bruce.,1986, Communication Systems, McGraw-Hill Book Company, New York

[2] David, Halliday dan Robert Resnick., 1985, Fisika Jilid 1 Edisis Ketiga, Diterjemahkan oleh Pantur Silaban dan Erwin Sucipto, ITB, Bandung

[3] Surjodiningrat, Wasisto, Sudarjana dan Adhi susanto. 1969, Penjelidikan dalam Pengukuran Nada Gamelan-gamelan Djawa Terkemuka di Jogjakarta dan Surakarta Laboratorium Akustik Bagian Mesin Fakultas Teknik Universitas Gadjah Mada Yogyakarta 